Check for updates

Cite this: RSC Adv., 2019, 9, 10245

\title{
Synthesis of new polyesters by acyclic diene metathesis polymerization of bio-based $\alpha, \omega$-dienes prepared from eugenol and castor oil (undecenoate) $\uparrow$
}

\author{
Duy Le, ${ }^{a}$ Chanatip Samart, ${ }^{\text {ab }}$ Suwadee Kongparakul ${ }^{* a b}$ and Kotohiro Nomura (DD *c \\ Synthesis of new polyesters by acyclic diene metathesis (ADMET) polymerization of $\alpha, \omega$-diene, 4-allyl-2- \\ methoxyphenyl 10-undecenoate (M1), prepared from bio-renewable eugenol and castor oil \\ (undecenoate), have been demonstrated. Ruthenium-carbene (called second generation Grubbs) catalyst \\ afforded polymers with unimodal molecular weight distributions $\left(M_{n}=12700, M_{w} / M_{n}=1.85\right)$. The \\ polymerization in the presence of a triarm cross-linker, 5-formylbenzene-1,2,3-triyl tris(undec-10- \\ enoate), also afforded polymers with certain uniform network structures.
}

Received 10th February 2019

Accepted 27th March 2019

DOI: $10.1039 / \mathrm{c} 9 \mathrm{ra} 01065 \mathrm{c}$

rsc.li/rsc-advances

carboxylate at the termini is an ideal substance for synthesis of high purity $\alpha, \omega$-dienes as valuable monomers for preparing polyesters via ADMET polymerization. For instance, ADMET polymerizations of castor oil-based $\alpha, \omega$-dienes (undecenyl-undecenoate) using second generation Grubbs-type ruthenium catalysts resulted in high molecular weight unsaturated polyesters have been investigated by Meier et al. ${ }^{12}$ The ADMET polymerization of $\alpha, \omega$-dienes prepared from castor-oil derivative with hydroxyl-bearing unsaturated compounds, diols and diamine have also been studied. ${ }^{13}$

Eugenol (UG, 4-allyl-2-methoxyphenol) is an interesting renewable resource obtained from clove oil. UG has been widely used not only in the production of cosmetics, perfumes, soaps, and even food, but also in the medical and pharmaceutical fields as antibiotic and antihypertensive agents. ${ }^{14}$ Owing to its functional groups [hydroxyl $(-\mathrm{OH})$, methoxy $\left(\mathrm{OCH}_{3}\right)$ and allyl groups], UG can be used as starting material for synthesis of new compounds exemplified in designing polymer networks via thiol-ene coupling ${ }^{15}$ or bismaleimide networks. ${ }^{16}$ Recently, study on UG mainly focused on Ru-catalysed olefin metathesis reactions such as self-metathesis ${ }^{17}$ and cross-metathesis with either electron-deficient olefins ${ }^{18}$ or unsaturated fatty acid methyl esters ${ }^{19}$ due to presence of the terminal olefin group. Therefore, it is possible to prepare different types of functionalized phenol derivatives to develop new routes for the production of different multifunctional products from UG. ${ }^{20}$ Additionally, UG structure, which contains an aromatic ring, has the potential alternative to petroleum-based phenolic monomers, which are widely used nowadays in the field of polyesters. For instance, a wide variety of polyesters based on UG and $\alpha, \omega$-diols have been prepared by polycondensation and thiol-ene click reactions. ${ }^{21}$ However, there are no reports had been published till date about using UG as the precursor for the 
synthesis of novel $\alpha, \omega$-dienes monomers incorporating with aliphatic chain (undecenoate) to produce polyesters via ADMET polymerization, although there is one report for ADMET polymerization of dieugenol derived from UG affording amorphous polymer with high molecular weight. ${ }^{22}$

In this paper, we wish to present a simple preparation of $\alpha, \omega$ diene monomer M1, derived from bio-renewable UG and castor oil, for synthesis of polyesters P1 by ADMET polymerization. The ADMET polymerization conditions in term of catalyst loading, type of catalyst and reaction time, have been investigated in detail. The ADMET polymerization of $\mathbf{M 1}$ in the presence of triarm cross-linker, 5-formylbenzene-1,2,3-triyl tris(undec-10enoate) was also studied. Two aliphatic polyesters with linear aliphatic $\alpha, \omega$-dienes were also prepared for comparison.

\section{Results and discussion}

In this study, 10-undecenoyl chloride (a derivative commercially available from undecenoic acid that can be obtained as a major component from castor oil $)^{8}$ has been chosen to prepare $\alpha, \omega$ diene monomer with eugenol (UG, obtained from clove oil). 5Hexen-1-ol and 10-undecen-1-ol ${ }^{12}$ instead of UG were also chosen for comparison. These monomers (expressed as M1-M3 in Scheme 1) were prepared in toluene in the presence of triethylamine according to the reported procedure, ${ }^{23}$ and the resultant compounds were purified by column chromatography, and were identified by NMR spectra and APCI mass spectrometry (shown in the Experimental section, and the selected spectra are also shown in the ESI, $\dagger) .{ }^{24}{ }^{1} \mathrm{H}$ NMR spectrum of the monomer, 4-allyl-2-methoxyphenyl 10-undecenoate (M1, Fig. 1a), shows characteristic resonances at 4.92-5.02 and 5.92-6.0 ppm, and 5.08-5.13 and 5.78-5.86 ppm ascribed to olefinic protons in terminal position; corresponding resonances ascribed to the carbons are also observed at 114.3 and 116.2 ppm, 139.3 and 137.2 ppm. $^{24}$ Similarly, reaction of 3,4,5trihydroxybenzaldehyde with 10-undecenoyl chloride in THF in the presence of excess triethylamine afforded the corresponding ester, 5-formylbenzene-1,2,3-triyl tris(undec-10-enoate) (CL), employed as the cross-linker in this study. CL was also identified by NMR spectra (Fig. 1b) ${ }^{24}$ and APCI mass spectrometry.

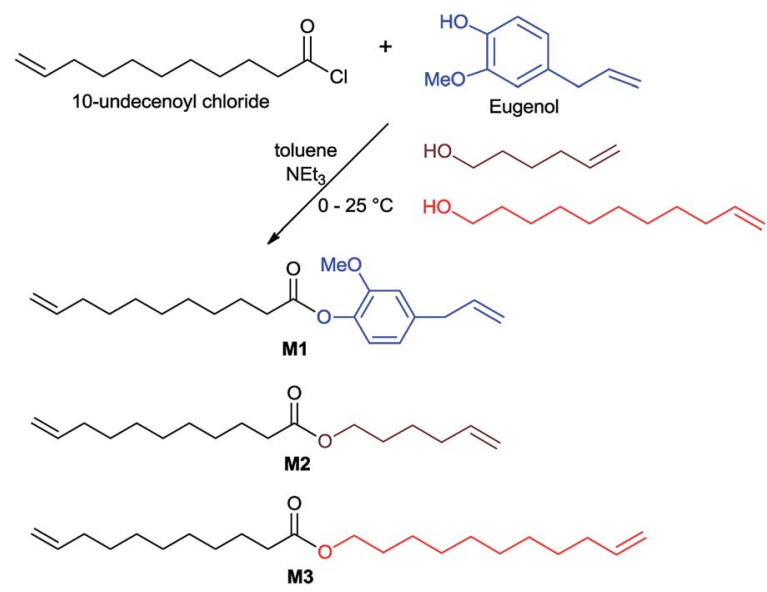

Scheme 1 Synthesis of monomers (M1-M3).

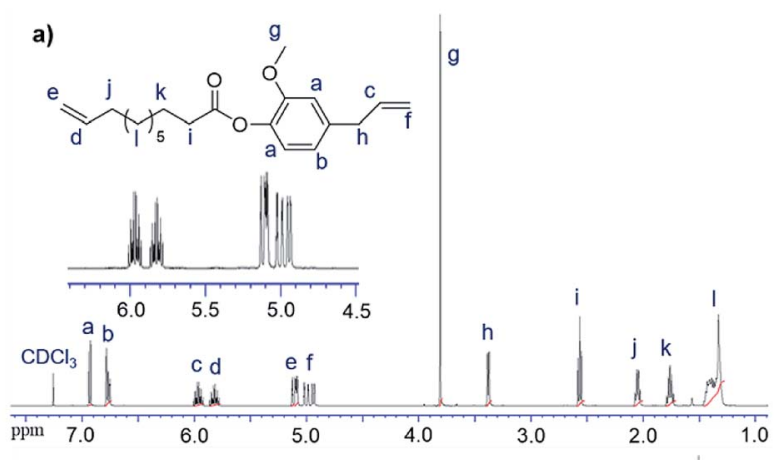

b)

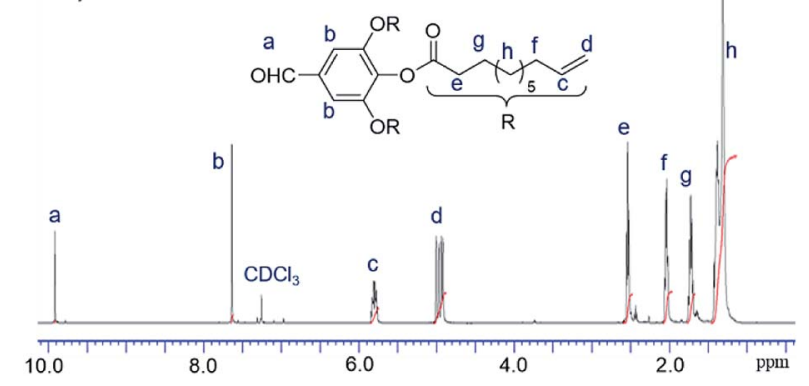

Fig. $1{ }^{1} \mathrm{H}$ NMR spectra (in $\mathrm{CDCl}_{3}$ at $25^{\circ} \mathrm{C}$ ) of (a) 4-allyl-2-methoxyphenyl 10-undecenoate (M1) and (b) 5-formylbenzene-1,2,3-triyl tris(undec-10-enoate) $(\mathrm{CL})$ with their peak assignments. ${ }^{24}$

Acyclic diene metathesis (ADMET) polymerizations of M1 were conducted in $\mathrm{CH}_{2} \mathrm{Cl}_{2}$ using a sealed Schlenk tube equipped with a high-vacuum valve in the presence of ruthenium catalyst (Scheme 2). ${ }^{24}$ The reactions were conducted in an oil bath heated at $50{ }^{\circ} \mathrm{C}$ under nitrogen atmosphere initially for a certain period ( $30 \mathrm{~min})$, and the mixture was then placed in vacuo to remove ethylene formed in this condensation polymerization (experimental details are described in the Experimental section), ${ }^{25}$ as conducted in synthesis of all-trans poly(9,9$n$-alkyl fluorene-2,7-vinylene)s by the ADMET polymerization. ${ }^{26}$ The results are summarized in Table $1 .^{24}$

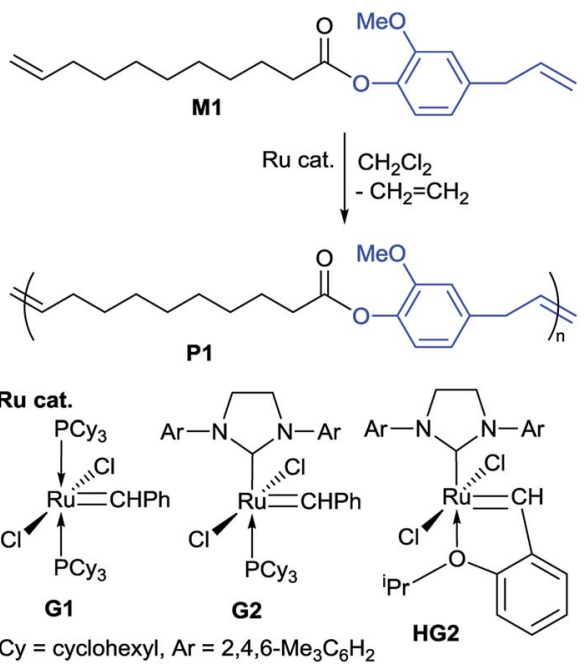

Scheme 2 Acyclic diene metathesis (ADMET) polymerization of M1 in the presence of Ru-carbene catalysts. 
Table 1 ADMET polymerization of 4-allyl-2-methoxyphenyl 10undecenoate (M1) by ruthenium catalysts ${ }^{a}$

\begin{tabular}{llllll}
\hline Run & Ru cat. $(\mathrm{mol} \%)^{b}$ & Time/h & $M_{\mathrm{n}}{ }^{c}$ & $M_{\mathrm{w}} / M_{\mathrm{n}}{ }^{c}$ & Yield $^{d} \%$ \\
\hline 1 & G2 (1.0) & 12 & 7100 & 1.74 & 86 \\
$2^{e}$ & G2 (1.0) & 12 & 8100 & 2.05 & 88 \\
3 & G2 (0.2) & 12 & 3200 & 3.63 & 55 \\
4 & G2 (0.5) & 12 & 7500 & 2.09 & 79 \\
5 & G2 (1.0) & 12 & 8100 & 2.05 & 88 \\
6 & G2 (1.5) & 3 & 9400 & 1.97 & 87 \\
7 & G2 (1.5) & 6 & 10300 & 1.95 & 87 \\
8 & G2 (1.5) & 12 & 12700 & 1.85 & 91 \\
9 & G2 (1.5) & 18 & 12400 & 1.64 & 87 \\
10 & G1 (1.5) & 12 & 5500 & 1.87 & 81 \\
11 & HG2 (1.5) & 12 & 4500 & 1.63 & 79 \\
12 & G2 (2.0) & 12 & 12500 & 1.84 & 91 \\
13 & G2 (3.0) & 12 & 7900 & 1.93 & 81
\end{tabular}

${ }^{a}$ Conditions: Ru catalyst (shown in Scheme 2), monomer M1 (330 mg, $1.0 \mathrm{mmol}$ ), $\mathrm{CH}_{2} \mathrm{Cl}_{2} 0.4 \mathrm{~mL}$ (initial monomer concentration $2.50 \mathrm{M}$ ), $50{ }^{\circ} \mathrm{C}$. Detailed procedure is shown in the Experimental section. ${ }^{b}$ Mol\% based on monomer M1. ${ }^{c}$ GPC data in THF $v s$. polystyrene standards. ${ }^{d}$ Isolated yield by precipitation as the methanol insoluble fraction. ${ }^{e}$ The tube was placed in vacuo twice at the first time (30 min).

It was revealed that the ADMET polymerization of M1 using called second generation Grubbs catalyst (G2) afforded polymers with unimodal molecular weight distributions $\left(M_{\mathrm{n}}=\right.$ 7100, 8100; $M_{\mathrm{w}} / M_{\mathrm{n}}=1.74,2.05$, respectively, runs 1, 2). Efficient removal of ethylene formed in this condensation polymerization seems beneficial for obtainment of high molecular weight polymers, because the $M_{\mathrm{n}}$ value seemed decreasing with increasing the initial reaction time under nitrogen $\left[M_{\mathrm{n}}, M_{\mathrm{w}} / M_{\mathrm{n}}\right.$ $=7100,1.87$ (1.0 h under $\mathrm{N}_{2}$ instead of $\left.30 \mathrm{~min}\right) ; M_{\mathrm{n}}, M_{\mathrm{w}} / M_{\mathrm{n}}=$ $6900,1.96\left(4.0 \mathrm{~h}\right.$ under $\mathrm{N}_{2}$ )] or the $M_{\mathrm{n}}$ value increased when ethylene was removed repeatedly after the initial reaction under nitrogen $\left[M_{\mathrm{w}} / M_{\mathrm{n}}=8100,2.05\right.$, run 2].

It was also revealed that the $M_{\mathrm{n}}$ value was also affected by the amount of ruthenium catalyst loaded (G2, runs 3-5, 8, 12, 13, Fig. 2a), and the polymerization in the presence of low $\mathrm{Ru}$ loading (0.2 mol\%) afforded low molecular weight oligomer (run 3, Fig. 2a). Moreover, the $M_{\mathrm{n}}$ value in the resultant polymer increased by increasing the $\mathrm{Ru}$ loading $\left[M_{\mathrm{n}}=7500(0.5 \mathrm{~mol} \%\right.$, run 4) vs. $M_{\mathrm{n}}=12700$ (1.5 mol\%, run 8)], and the GPC traces became unimodal upon increasing the $\mathrm{Ru}$ loading as clearly demonstrated in Fig. 2a. It thus turned out that the optimized conditions concerning the amount of Ru are 1.5 or $2.0 \mathrm{~mol} \%$ (based on M1, runs 8 and 12) for obtainment of high molecular

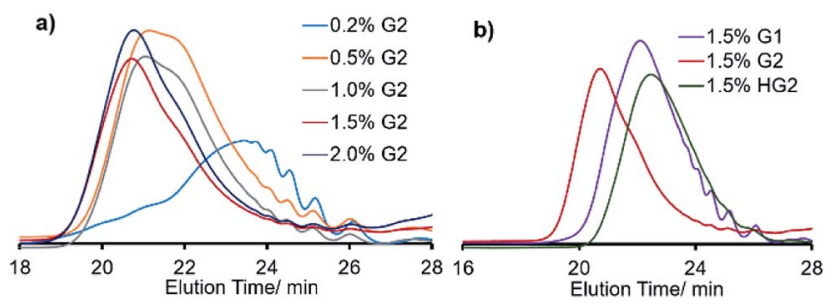

Fig. 2 GPC traces of polymers (P1) in ADMET polymerization of M1 under (a) effect of different G2 loading, and (b) effect of Ru catalysts. Detailed data are shown in Table 1. weight polymers with unimodal molecular weight distributions. The $M_{\mathrm{n}}$ value was also affected by the reaction time (runs 6-9), and no significant increase in the $M_{\mathrm{n}}$ value was observed after $12 \mathrm{~h}$ (runs 8, 9). It also turned out, under the above optimized conditions (run 8), that the other ruthenium catalysts (expressed as G1, and HG2 in Scheme 2) afforded polymers with rather low molecular weights (runs 10, 11, respectively, Fig. 2b). This would be probably because of low reactivity of G1 toward olefins in this ADMET polymerization. ${ }^{27}$ It also seems likely that rather low catalyst efficiency by HG2 compared to G2 might be considered for the explanation under these conditions. Therefore, $\mathbf{G} 2$ seems to be the most suitable in terms of synthesis of higher molecular weight polymers with unimodal molecular weight distributions.

Fig. 3 shows ${ }^{1} \mathrm{H}$ NMR spectrum (in $\mathrm{CDCl}_{3}$ at $25^{\circ} \mathrm{C}$ ) for 4 -allyl2-methoxyphenyl 10-undecenoate (M1, Fig. 3a) and the resultant polymer (P1, Fig. 3b) prepared by ADMET polymerization (sample run 8). Resonances ascribed to protons of terminal olefins (at 4.92-5.02 and 5.92-6.0 ppm, and 5.08-5.13 and 5.78$5.86 \mathrm{ppm}$ ) disappeared and resonances ascribed to protons assigned to internal olefins (at 5.35-5.67 and 6.15-6.45 ppm, placed as dashed circle in Fig. 3b) were observed, whereas the other resonances were remained. The results thus clearly indicate formation of polymers by the ADMET polymerization. ${ }^{25,27}$ As also suggested by the NMR spectra (broad and several resonances ascribed to olefinic protons), the resultant polymers do not have regular structures in almost certainly but are probably a mixture of head-to-head, head-to-tail, and tail-to-tail arrangement of the repeat unit containing cis and trans double bonds. This can also be suggested by ${ }^{13} \mathrm{C}$ NMR spectrum in P1 (resonances ascribed to internal olefinic carbons at 128141 ppm, Fig. S10 in ESI $\dagger$ ). ${ }^{24}$ The fact might also explain additional resonances in the aliphatic region (marked with *) compared to M1 in Fig. 3b. The resultant polymer (P1) possesses glass transition temperature $\left(T_{\mathrm{g}}\right)$ at $-9.6^{\circ} \mathrm{C}$ by the DSC thermogram (sample run 8, shown in ESI $\dagger$ ), ${ }^{24}$ and no melting

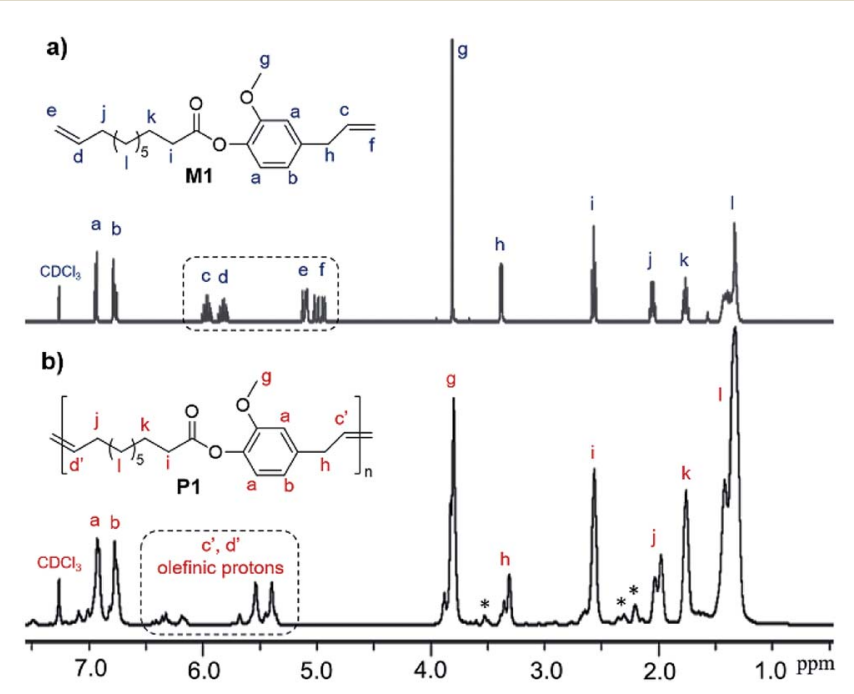

Fig. $3{ }^{1} \mathrm{H}$ NMR spectrum (in $\mathrm{CDCl}_{3}$ at $25{ }^{\circ} \mathrm{C}$ ) for (a) 4-allyl-2methoxyphenyl 10-undecenoate (M1), and (b) the resultant polymer (P1) prepared by the ADMET polymerization (run 8). 
temperature was observed, suggesting that P1 is amorphous material with uniform composition.

Table 2 summarizes the results for ADMET polymerizations of monomers $\mathbf{M} 2$ and $\mathbf{M} 3^{12}$ in the presence of rutheniumcarbene catalyst (G2, Scheme 3). It was revealed that the polymerizations of M2 afforded polymers with unimodal molecular weight distributions (e.g. $M_{\mathrm{n}}=8300 M_{\mathrm{w}} / M_{\mathrm{n}}=1.52$, run 14) under optimized conditions. As observed in the ADMET polymerization of M1, in the polymerization of $\mathbf{M} 2$, the $M_{\mathrm{n}}$ value was affected by the amount of ruthenium catalyst charged, and the $M_{\mathrm{n}}$ value in the resultant polymer (P2) increased by increasing the Ru loading $\left[M_{\mathrm{n}}=8300\right.$ (2.0 mol\%, run 14) vs. $M_{\mathrm{n}}=7300$ $(0.5 \mathrm{~mol} \%$, run 16$)]$. In contrast, in the polymerization of $\mathbf{M 3},{ }^{12}$ the optimized conditions seem $0.5 \mathrm{~mol} \%$ (run 19) for obtainment of rather high molecular weight polymer (P3) with unimodal molecular weight distribution. Both ${ }^{1} \mathrm{H}$ and ${ }^{13} \mathrm{C}$ NMR spectra clearly support formation of polymers by the ADMET polymerization (disappearance of resonances ascribed to terminal olefins and observed resonances assigned to internal olefins, the spectra are shown in the ESI, $\dagger) .{ }^{24}$ DSC thermograms in the resultant polymers (P2, P3) show a melting temperature $\left(T_{\mathrm{m}}\right)$ at $14.3{ }^{\circ} \mathrm{C}(\mathbf{P} 2$, sample run 14$), 51.5{ }^{\circ} \mathrm{C}(\mathbf{P 3}$, sample run 19$)$,

Table 2 ADMET polymerization of M2 and M3 by G2 catalyst ${ }^{a}$

\begin{tabular}{llllll}
\hline Run & Monomer & $\mathbf{G 2} / \mathrm{mol}^{b}$ & $M_{\mathrm{n}}{ }^{c}$ & $M_{\mathrm{w}} / M_{\mathrm{n}}{ }^{c}$ & Yield $^{d} / \%$ \\
\hline 14 & M2 & 2.0 & 8300 & 1.52 & 71 \\
15 & M2 & 1.0 & 7700 & 1.49 & 71 \\
16 & M2 & 0.5 & 7300 & 1.44 & 72 \\
17 & M3 & 2.0 & 6200 & 1.50 & 78 \\
18 & M3 & 1.0 & 6900 & 1.53 & 78 \\
19 & M3 & 0.5 & 8500 & 1.64 & 84 \\
20 & M3 & 0.2 & 7200 & 1.55 & 83
\end{tabular}

${ }^{a}$ Conditions: monomer M2 (266 mg, $\left.1.0 \mathrm{mmol}\right)$ or M3 (336 mg, 1.0 $\mathrm{mmol}$ ), $\mathrm{CH}_{2} \mathrm{Cl}_{2} 0.4 \mathrm{~mL}$ (initial monomer concentration $2.50 \mathrm{M}$ ), $50{ }^{\circ} \mathrm{C}$, $12 \mathrm{~h}$. Detailed procedure is shown in the Experimental section. ${ }^{b}$ Mol\% based on monomer. ${ }^{c}$ GPC data in THF vs. polystyrene standards. ${ }^{d}$ Isolated yield by precipitation as the methanol insoluble fraction.
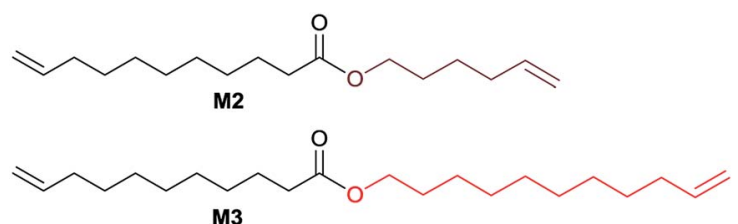

Ru cat. $\mid \mathrm{CH}_{2} \mathrm{Cl}_{2}$

G2 $\downarrow-\mathrm{CH}_{2}=\mathrm{CH}_{2}$
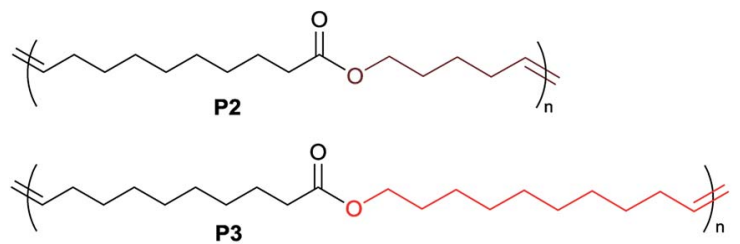

Scheme 3 Acyclic diene metathesis (ADMET) polymerization of M2 and $\mathrm{M} 3$ in the presence of Ru-carbene catalyst (G2). respectively, as observed in long-chain aliphatic polyesters. ${ }^{28,29}$ In general the melting temperature ( $T_{\mathrm{m}}$ value) in the polyester increases with increasing hydrocarbon chain length, ${ }^{30}$ and the $T_{\mathrm{m}}$ value in the polyester consisting of two types of methylene units also affected the distribution. ${ }^{31}$ Therefore, increase in the $T_{\mathrm{m}}$ value from $\mathbf{P} 2$ to $\mathbf{P} 3$ would be due to increase of methylene chain length. However, observed $T_{\mathrm{m}}$ values might be rather low probably due to that microstructure in the resultant polymers are a mixture of head-to-tail, head-to-head and tail-to-tail repeat units. In contrast, placing phenyl group into the polymer main chain in P1 afforded the amorphous materials.

In order to demonstrate a possibility of synthesis of crosslinked polymers (often employed to improve mechanical properties etc.), ADMET polymerizations of 4-allyl-2-methoxyphenyl 10-undecenoate (M1) were conducted in the presence of crosslinker (CL), prepared by reaction of 3,4,5-trihydroxybenzaldehyde with 10-undecenoyl chloride in this study (Scheme 4). The results are summarized in Table $3 .^{24}$

It was revealed that $M_{\mathrm{n}}$ value in the resultant polymer (P1) slightly increased in the presence of $\mathbf{C L}\left[M_{\mathrm{n}}=12700\right.$ (run 8) vs. 13300 (run 21), reaction $12 \mathrm{~h}$, CL $2.5 \mathrm{~mol} \%$ ], and further stirring afforded polymer with low PDI $\left(M_{\mathrm{w}} / M_{\mathrm{n}}\right)$ value (run 22, reaction $18 \mathrm{~h}$ ). Increasing the amount of $\mathbf{C L}$ (from 2.5 to $5.0 \mathrm{~mol} \%$ ) afforded the polymers with rather broad molecular

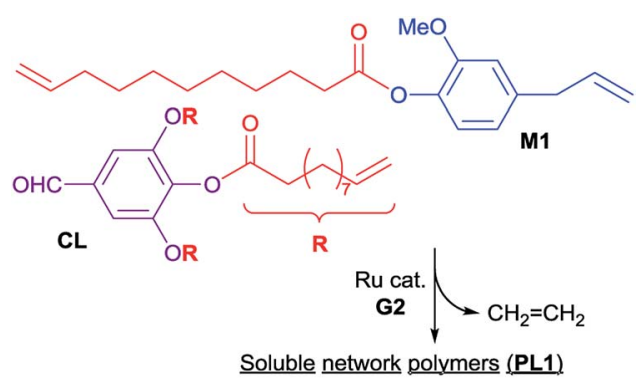

Scheme 4 Acyclic diene metathesis (ADMET) polymerization of 4allyl-2-methoxyphenyl 10-undecenoate (M1) in the presence of 5formylbenzene-1,2,3-triyl tris(undec-10-enoate) (CL).

Table 3 ADMET polymerization of M1 using G2 in the presence of cross-linker $(\mathrm{CL})^{a}$

\begin{tabular}{llllll}
\hline Run & $\mathbf{C L}^{b} / \mathrm{mol} \%$ & Time $/ \mathrm{h}$ & $M_{\mathrm{n}}{ }^{c}$ & $M_{\mathrm{w}} / M_{\mathrm{n}}{ }^{c}$ & Yield $^{d} / \%$ \\
\hline 8 & - & 12 & 12700 & 1.85 & 91 \\
21 & 2.5 & 12 & 13300 & 2.58 & 88 \\
22 & 2.5 & 18 & 13600 & 2.28 & 89 \\
23 & 5.0 & 12 & 11500 & 3.95 & 88 \\
24 & 5.0 & 18 & 13500 & 3.48 & 88 \\
$25^{e}$ & 5.0 & 18 & 13800 & 2.80 & 90 \\
$26^{f}$ & 5.0 & 18 & 10200 & 2.05 & 81 \\
$27^{f}$ & 5.0 & 24 & 11800 & 2.59 & 86
\end{tabular}

${ }^{a}$ Conditions: monomer M1 (330 mg, $1.0 \mathrm{mmol}$ ), ruthenium catalyst (G2) $1.5 \mathrm{~mol} \%$, cross-linker (CL), $\mathrm{CH}_{2} \mathrm{Cl}_{2} 0.4 \mathrm{~mL}$ (initial monomer concentration $2.50 \mathrm{M}$ ), $50{ }^{\circ} \mathrm{C}$. Detailed procedure is shown in the Experimental section. ${ }^{b}$ Mol\% based on monomer M1. ${ }^{c}$ GPC data in THF $v s$. polystyrene standards. ${ }^{d}$ Isolated yield by precipitation as the methanol insoluble fraction. ${ }^{e} \mathrm{Ru} 2.0 \mathrm{~mol} \%$. ${ }^{f}$ Cross-linker (CL, $5.0 \mathrm{~mol} \%$ ) was added after $30 \mathrm{~min}$. 
weight distributions even after $18 \mathrm{~h}$ (runs 23, 24), and no significant increase in the $M_{\mathrm{n}}$ values were observed (runs 2124). However, as shown in Fig. 4, GPC traces in the resultant polymers, it seems that the molecular weight distributions became unimodal after $18 \mathrm{~h}$; the PDI value became low upon increasing the Ru loading (run 25). It turned out that increase of $\mathrm{Ru}$ loading (run 25), addition of $\mathbf{C L}$ after the initial ADMET polymerization did not affect the increase of $M_{\mathrm{n}}$ value in the resultant polymers.

Fig. 5 shows ${ }^{1} \mathrm{H}$ NMR spectra (in $\mathrm{CDCl}_{3}$ at $25{ }^{\circ} \mathrm{C}$ ) of $\mathbf{P 1}$ (sample run 8) and PL1 (sample run 24). As observed in P1 (Fig. 3b), protons assigned to terminal olefins in $\mathbf{M 1}$ and $\mathbf{C L}$ were disappeared and resonances ascribed to protons in the internal olefins were observed (placed as dashed circle in Fig. 5b and c). Moreover, resonances ascribed to CL (in particular protons corresponding to aldehyde and aromatic proton marked as $*$ in Fig. 5a and c) were clearly observed. ${ }^{24}$ DSC thermograms in the resultant polymer (PL1) show a glass transition temperature $\left(T_{\mathrm{g}}\right)$ at $-10.5{ }^{\circ} \mathrm{C}$, which is relatively close to that in $\mathbf{P 1}\left(T_{\mathrm{g}}=-9.6{ }^{\circ} \mathrm{C}\right) .{ }^{24}$ These results thus probably suggest that PL1 possesses a certain network structure consisting of P1 and CL (with low degree of cross-linking) with

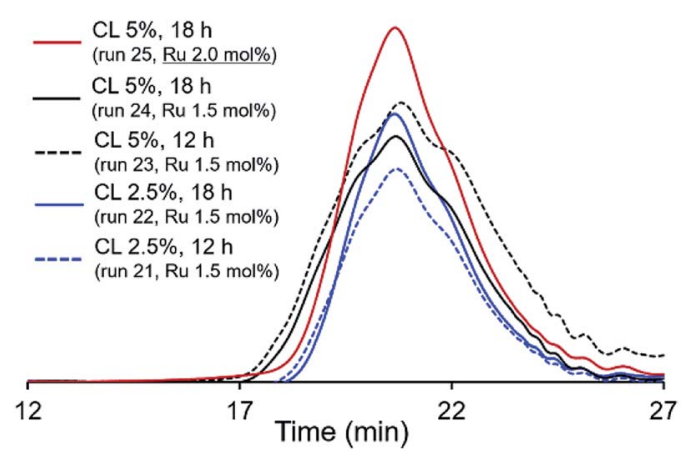

Fig. 4 GPC traces polymers (PL1) in ADMET polymerization of M1 using $\mathrm{G} 2$ in the presence of cross-linker (CL). Detailed data are shown in Table 3.

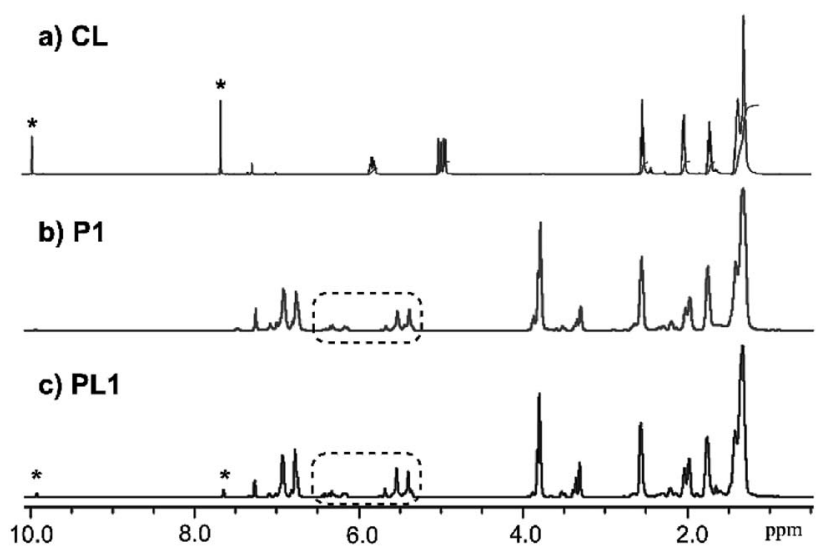

Fig. $5{ }^{1} \mathrm{H} \mathrm{NMR}$ spectra (in $\mathrm{CDCl}_{3}$ at $25^{\circ} \mathrm{C}$ ) for (a) cross-linker (CL), (b) the resultant polymer (P1) prepared by ADMET polymerization of $\mathrm{M} 1$ (run 8), and (c) resultant polymer (PL1) prepared by the ADMET polymerization of $\mathrm{M} 1$ in the presence of $\mathrm{CL}(5.0 \mathrm{~mol} \%$, sample run 24$)$. uniform composition. The resultant polymer sample (PL1) was hardly soluble in $\mathrm{CDCl}_{3}(30 \mathrm{mg} / 2.0 \mathrm{~mL})$ at room temperature but became completely soluble overnight, whereas the sample is easily soluble in THF for GPC measurement.

\section{Conclusions}

We have shown that synthesis of new polyesters by ADMET polymerization of $\alpha, \omega$-dienes, 4-allyl-2-methoxyphenyl 10undecenoate (M1), prepared from bio-renewable eugenol (obtained from clove oil) and 10-undecenoic acid derivative (obtained from castor oil). Ruthenium-carbene (called second generation Grubbs) catalyst afforded polymers with unimodal molecular weight distributions $\left(M_{\mathrm{n}}=12700, M_{\mathrm{w}} / M_{\mathrm{n}}=1.85\right)$. The polymerization of $\mathbf{M 1}$ in the presence of triarm cross-linker, 5-formylbenzene-1,2,3-triyl tris(undec-10-enoate), also afforded certain network polymers, suggested by NMR spectra and DSC thermogram. Since 9-decenoate obtained from the other vegetable oil (e.g. methyl oleate) by ethenolysis, should be used in place of 10-undecenoate, also since, as described in the introductory, further chemical modification can be possible from functional group (methoxy group) in the resultant polymers (P1, PL1), we thus believe that the present approach is promising and should be applicable for synthesis of polyesters from monomers prepared from bio-renewable resources.

\section{Experimental section}

\section{General experimental considerations}

All experiments were carried out under nitrogen atmosphere or using standard Schlenk techniques unless otherwise specified. Anhydrous grade dichloromethane and toluene (>99.5\%, Kanto Chemical Co., Inc.) were transferred into a bottle containing molecular sieves (mixture of 3A 1/16, 4A 1/8 and 13X 1/16) in the drybox. $\mathrm{RuCl}_{2}\left(\mathrm{PCy}_{3}\right)_{2}(\mathrm{CHPh})$ (called $1^{\text {st }}$ generation Grubbs catalyst (G1); Cy = cyclohexyl), $\mathrm{RuCl}_{2}\left(\mathrm{PCy}_{3}\right)\left(\mathrm{H}_{2} \mathrm{IMes}\right)(\mathrm{CHPh})$ [called $2^{\text {nd }}$ generation Grubbs catalyst (G2); $\mathrm{IMesH}_{2}=1,3$ bis(2,4,6-trimethylphenyl)imidazolin-2-ylidene] and $\mathrm{RuCl}_{2}(-$ $\left.\mathrm{IMesH}_{2}\right)\left(\mathrm{CH}-2-\mathrm{O}^{i} \mathrm{Pr}-\mathrm{C}_{6} \mathrm{H}_{4}\right) \quad$ [called $2^{\text {nd }}$ generation HoveydaGrubbs catalyst (HG2)] were purchased from Aldrich Chemical Co., and were used as received. Chemicals of reagent grades such as Eugenol (UG, >99.0\%, Tokyo Chemical Industry, Co., Ltd.), 10-undecenoyl chloride (UDC, >99\%), 10-undecen-1-ol (UDO, >98\%), 5-hexene-1-ol (Hex), 3,4,5-trihydroxybenzaldehyde $(>98 \%)$ and triethylamine $\left(\mathrm{NEt}_{3},>99 \%\right)$ were obtained from Tokyo Chemical Industry, Co., Ltd., and were used as received. Ethyl vinyl ether (>98\%) and Celite were purchased from Wako Pure Chemical Industries, Ltd.

All ${ }^{1} \mathrm{H}$ and ${ }^{13} \mathrm{C}$ NMR spectra were recorded using a Bruker AV500 spectrometer (500.13 $\mathrm{MHz}$ for ${ }^{1} \mathrm{H}, 125.77 \mathrm{MHz}$ for ${ }^{13} \mathrm{C}$ ). All chemical shifts were reported in parts per million (ppm) with referenced to $\mathrm{SiMe}_{4}$ (TMS) at $0.00 \mathrm{ppm}$. Obvious multiplicities and routine coupling constants are usually not listed, and all spectra were obtained in the solvent indicated at $25{ }^{\circ} \mathrm{C}$ unless otherwise noted. Molecular weights and the molecular weight distributions of the resultant polymers were measured by gelpermeation chromatography (GPC). GPC measurements were 
performed at $40{ }^{\circ} \mathrm{C}$ on a Shimadzu SCL-10A using a RID-10A detector (Shimadzu Co., Ltd.) in THF (containing $0.03 \mathrm{wt} \%$ of 2,6-di-tert-butyl-p-cresol, flow rate $1.0 \mathrm{~mL} \mathrm{~min}^{-1}$ ). HPLC grade THF (Wako Pure Chemical Ind., Inc.) was used as the eluent

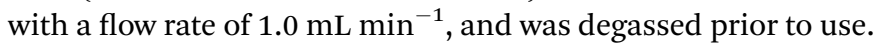
GPC columns (ShimPAC GPC-806, 804 and 802, $30 \mathrm{~cm} \times$ $8.0 \mathrm{~mm}$ diameter, spherical porous gel made of styrene/ divinylbenzene copolymer, ranging from $<10^{2}$ to $2 \times 10^{7} \mathrm{MW}$ ) were calibrated versus polystyrene standard samples. Differential scanning calorimetric (DSC) data for polymer were measured using a Hitachi DSC 7020 analyzer. Nitrogen was used as purge gas and all samples (5-7 mg) were placed in standard aluminium pans. Polymer samples were first heated from 25 to $250{ }^{\circ} \mathrm{C}$ then cooled to $-100{ }^{\circ} \mathrm{C}$. The glass transition $\left(T_{\mathrm{g}}\right)$ and melting $\left(T_{\mathrm{m}}\right)$ temperature were determined upon second heating cycle. All runs were performed at a rate of $10{ }^{\circ} \mathrm{C} \mathrm{min}^{-1}$. Atmospheric pressure chemical ionization (APCI) mass spectrometry was performed on Bruker MicroTOF IISDT1.

\section{Synthesis of 4-allyl-2-methoxyphenyl undec-10-enoate (M1)}

10-undecenoyl chloride (3.04 g, $15 \mathrm{mmol}$ ) was added dropwise into a toluene solution $(15.0 \mathrm{~mL})$ containing eugenol $(2.46 \mathrm{~g}, 15$ $\mathrm{mmol})$ and triethylamine $(2.51 \mathrm{~mL}, 18 \mathrm{mmol})$ over $30 \mathrm{~min}$ at $0{ }^{\circ} \mathrm{C}$. The mixture was then warmed to room temperature and was stirred for $4 \mathrm{~h}$. After the reaction was reached to completion, by confirmation of consumption of 10-undecenoyl chloride by TLC, the reaction mixture was then neutralized with $2 \mathrm{~N}$ $\mathrm{HCl}$, and was washed with $5 \% \mathrm{NaHCO}_{3}(15 \mathrm{~mL} \times 3)$, deionized water $(15 \mathrm{~mL} \times 4)$, was then with brine $(15 \mathrm{~mL} \times 2)$. The solution was dried over anhydrous $\mathrm{MgSO}_{4}$, and was then filtered through a Celite pad, and the filtrate was evaporated under reduced pressure. The crude product was purified by column chromatography using hexane/ethyl acetate (9/1) as an eluent to yield M1 as colorless oil (3.87 g, 78\% yield). ${ }^{1} \mathrm{H}$ NMR $\left(\mathrm{CDCl}_{3}\right)$ : $\delta 1.33\left(\mathrm{~s}, 10 \mathrm{H}, 5 \mathrm{CH}_{2}\right.$ ) 1.75-1.79 (quint, $J=7.5 \mathrm{~Hz}, 2 \mathrm{H}, \mathrm{CH}_{2}$ ), 2.03-2.07 (quart, $J=7.5 \mathrm{~Hz}, 2 \mathrm{H}, \mathrm{CH}_{2} \mathrm{CH}=\mathrm{CH}_{2}$ ), 2.55-2.58 (t, $J=$ $7.5 \mathrm{~Hz}, 2 \mathrm{H},-\mathrm{CH}_{2} \mathrm{COO}-$ ), $3.37-3.38$ (d, $J=6.8 \mathrm{~Hz}, 2 \mathrm{H}, \mathrm{Ar}-\mathrm{CH}_{2}$ ), $3.81\left(\mathrm{~s}, 3 \mathrm{H}, \mathrm{OCH}_{3}\right), 4.92-5.02\left(\mathrm{~m}, 2 \mathrm{H}, \mathrm{Ar}-\mathrm{CH}_{2} \mathrm{CH}=\mathrm{CH}_{2}\right), 5.08-$ $5.13\left(2 \mathrm{H},-\mathrm{CH}=\mathrm{CH}_{2}\right), 5.78-5.86(\mathrm{~m}, J=6.68,6.68$ and $6.77 \mathrm{~Hz}$, $\left.1 \mathrm{H},-\mathrm{CH}=\mathrm{CH}_{2}\right), 5.92-6.0(\mathrm{~m}, J=6.75,6.75$ and $6.79 \mathrm{~Hz}, 1 \mathrm{H}, \mathrm{Ar}-$ $\mathrm{CH}_{2} \mathrm{CH}=\mathrm{CH}_{2}$ ), 6.75-6.79 (m, 1HAr, $\left.\mathrm{CH}\right)$, 6.93-6.94 ppm (m, 2HAr, $2 \mathrm{CH}) .{ }^{13} \mathrm{C}\left\{{ }^{1} \mathrm{H}\right\}$ NMR $\left(\mathrm{CDCl}_{3}\right): \delta 25.1\left(\mathrm{CH}_{2}\right), 29.0\left(\mathrm{CH}_{2}\right), 29.1$ $\left(\mathrm{CH}_{2}\right), 29.3\left(\mathrm{CH}_{2}\right), 29.4\left(\mathrm{CH}_{2}\right), 33.9\left(\mathrm{CH}_{2} \mathrm{COO}-\right), 34.1\left(\mathrm{CH}_{2}\right), 40.2$ $\left(\mathrm{Ar}-\mathrm{CH}_{2}\right), 55.9\left(\mathrm{OCH}_{3}\right), 112.8(\mathrm{CH}), 114.3\left(\mathrm{CH}=\mathrm{CH}_{2}\right), 116.2(\mathrm{Ar}-$ $\left.\mathrm{CH}_{2} \mathrm{CH}=\mathrm{CH}_{2}\right), 120.7(\mathrm{CH}), 122.6(\mathrm{CH}), 137.2\left(\mathrm{Ar}-\mathrm{CH}_{2} \mathrm{CH}=\right.$ $\mathrm{CH}_{2}$ ), $138.2(\mathrm{Ar}), 138.9(\mathrm{Ar}), 139.3\left(\mathrm{CH}=\mathrm{CH}_{2}\right), 151.0(\mathrm{Ar})$, 172.1 ppm (-COO-). APCI-MS: calculated for $\mathrm{C}_{21} \mathrm{H}_{30} \mathrm{O}_{3}[\mathrm{M}+\mathrm{H}]^{+}$ 331.2; found 331.2 .

\section{Synthesis of 5-hexen-1-yl 10-undecenoate (M2)}

10-undecenoyl chloride (3.04 g, $15 \mathrm{mmol}$ ) was added dropwise into a toluene solution $(20.0 \mathrm{~mL})$ containing 5-hexen-1-ol $(1.50 \mathrm{~g}, 15 \mathrm{mmol})$ and triethylamine $(2.51 \mathrm{~mL}, 18 \mathrm{mmol})$ over $30 \mathrm{~min}$ at $0{ }^{\circ} \mathrm{C}$. The mixture was then warmed to room temperature and was stirred for $2.5 \mathrm{~h}$. After the reaction was reached to completion, by confirmation of consumption of 10undecenoyl chloride by TLC, the reaction mixture was then neutralized with $2 \mathrm{~N} \mathrm{HCl}$, and was washed with $5 \% \mathrm{NaHCO}_{3}$ $(15 \mathrm{~mL} \times 3)$, deionized water $(15 \mathrm{~mL} \times 4)$, was then with brine $(15 \mathrm{~mL} \times 2)$. The solution was dried over anhydrous $\mathrm{MgSO}_{4}$, and was then filtered through a Celite pad, and the filtrate was evaporated under reduced pressure. The crude product was purified by column chromatography using hexane/ethyl acetate (9/1) as an eluent to yield $\mathbf{M} 2$ as a colorless oil (3.24 g, 81\% yield). ${ }^{1} \mathrm{H}$ NMR (500 MHz, $\left.\mathrm{CDCl}_{3}, \mathrm{ppm}\right): \delta 1.28-1.36(\mathrm{~s}, 10 \mathrm{H}$, 5CH $\left.\mathrm{CH}_{2}\right), 1.44\left(\mathrm{~m}, 2 \mathrm{H}, \mathrm{CH}_{2}\right), 1.61-1.64\left(\mathrm{~m}, 4 \mathrm{H}, 2 \mathrm{CH}_{2}\right), 2.02-2.08$ $\left(\mathrm{m}, J=15.2\right.$ and $\left.16.9 \mathrm{~Hz}, 4 \mathrm{H}, 2 \mathrm{CH}_{2} \mathrm{CH}=\mathrm{CH}_{2}\right), 2.26-2.29(\mathrm{t}, J=$ $\left.7.4 \mathrm{~Hz}, 2 \mathrm{H},-\mathrm{CH}_{2} \mathrm{COO}-\right), 4.06\left(\mathrm{t}, J=6.5 \mathrm{~Hz}, 2 \mathrm{H},-\mathrm{COOCH}_{2}-\right)$, 4.91-5.02 (m, $J=8.8$ and $\left.14.0 \mathrm{~Hz}, 4 \mathrm{H}, 2 \mathrm{CH}_{2}=\mathrm{CH}-\right)$, 5.77$5.80 \mathrm{ppm}\left(\mathrm{m}, J=1.4\right.$ and $\left.11.6 \mathrm{~Hz}, 2 \mathrm{H}, 2 \mathrm{CH}_{2}=\mathrm{CH}-\right) .{ }^{13} \mathrm{C}\left\{{ }^{1} \mathrm{H}\right\}$ NMR (125 MHz, $\left.\mathrm{CDCl}_{3}, \mathrm{ppm}\right): \delta 25.1\left(\mathrm{CH}_{2}\right), 25.3\left(\mathrm{CH}_{2}\right), 28.2$ $\left(\mathrm{CH}_{2}\right), 29.0\left(\mathrm{CH}_{2}\right), 29.2\left(\mathrm{CH}_{2}\right), 29.3\left(\mathrm{CH}_{2}\right), 29.4\left(\mathrm{CH}_{2}\right), 33.4\left(\mathrm{CH}_{2}\right)$, $33.9\left(\mathrm{CH}_{2}\right), 34.5\left(\mathrm{CH}_{2}\right), 64.2\left(-\mathrm{COOCH}_{2}-\right), 114.3\left(\mathrm{CH}=\mathrm{CH}_{2}\right)$, $139.3\left(\mathrm{CH}=\mathrm{CH}_{2}\right), 174.1$ (-COO-). APCI-MS: calculated for $\mathrm{C}_{17} \mathrm{H}_{30} \mathrm{O}_{2}[\mathrm{M}+\mathrm{H}]^{+}$267.2; found 267.2.

\section{Synthesis of 10-undecen-1-yl 10-undecenoate (M3)}

10-undecenoyl chloride (3.04 g, $15 \mathrm{mmol}$ ) was added dropwise into a toluene solution $(20.0 \mathrm{~mL})$ containing 10-undecen-1-ol $(2.55 \mathrm{~g}, 15 \mathrm{mmol})$ and triethylamine $(2.51 \mathrm{~mL}, 18 \mathrm{mmol})$ over $30 \mathrm{~min}$ at $0{ }^{\circ} \mathrm{C}$. The mixture was then warmed to room temperature and was stirred for $2.5 \mathrm{~h}$. After the reaction was reached to completion, by confirmation of consumption of 10undecenoyl chloride by TLC, the reaction mixture was then neutralized with $2 \mathrm{~N} \mathrm{HCl}$, and was washed with $5 \% \mathrm{NaHCO}_{3}$ $(15 \mathrm{~mL} \times 3)$, deionized water $(15 \mathrm{~mL} \times 4)$, was then with brine $(15 \mathrm{~mL} \times 2)$. The solution was dried over anhydrous $\mathrm{MgSO}_{4}$, and was then filtered through a Celite pad, and the filtrate was evaporated under reduced pressure. The crude product was purified by column chromatography using hexane/ethyl acetate (9/1) as an eluent to yield $\mathbf{M 3}$ as a colorless oil (4.26 g, 85\% yield). ${ }^{1} \mathrm{H}$ NMR (500 MHz, $\left.\mathrm{CDCl}_{3}, \mathrm{ppm}\right): \delta 1.27-1.36(\mathrm{~s}, 22 \mathrm{H}$, $\left.11 \mathrm{CH}_{2}\right), 1.60\left(\mathrm{~s}, 4 \mathrm{H}, 2 \mathrm{CH}_{2}\right), 2.02-2.03(\mathrm{~d}, J=6.4 \mathrm{~Hz}, 4 \mathrm{H}$, $\left.2 \mathrm{CH}_{2} \mathrm{CH}=\mathrm{CH}_{2}\right), 2.26-2.29\left(\mathrm{t}, J=7.4 \mathrm{~Hz}, 2 \mathrm{H},-\mathrm{CH}_{2} \mathrm{COO}-\right), 4.03-$ $4.05\left(\mathrm{t}, J=6.6 \mathrm{~Hz}, 2 \mathrm{H},-\mathrm{COOCH}_{2}-\right), 4.90-4.99(\mathrm{~m}, J=9.3$ and $\left.17.1 \mathrm{~Hz}, 4 \mathrm{H}, 2 \mathrm{CH}_{2}=\mathrm{CH}-\right)$, 5.76-5.81 ppm (d, $J=6.8 \mathrm{~Hz}, 2 \mathrm{H}$, $\left.2 \mathrm{CH}_{2}=\mathrm{CH}-\right) .{ }^{13} \mathrm{C}\left\{{ }^{1} \mathrm{H}\right\}$ NMR (125 $\left.\mathrm{MHz}, \mathrm{CDCl}_{3}, \mathrm{ppm}\right): \delta 26.0$ $\left(\mathrm{CH}_{2}\right), 28.8\left(\mathrm{CH}_{2}\right), 29.0\left(\mathrm{CH}_{2}\right), 29.1\left(\mathrm{CH}_{2}\right), 29.2\left(\mathrm{CH}_{2}\right), 29.3\left(\mathrm{CH}_{2}\right)$, $29.4\left(\mathrm{CH}_{2}\right), 29.5\left(\mathrm{CH}_{2}\right), 29.6\left(\mathrm{CH}_{2}\right), 33.9\left(\mathrm{CH}_{2}\right), 34.5\left(\mathrm{CH}_{2}\right), 64.5$ $\left(-\mathrm{COOCH}_{2}-\right), 114.2\left(\mathrm{CH}=\mathrm{CH}_{2}\right), 139.2\left(\mathrm{CH}=\mathrm{CH}_{2}\right), 174.0 \mathrm{ppm}$ (-COO-). APCI-MS: calculated for $\mathrm{C}_{22} \mathrm{H}_{40} \mathrm{O}_{2}[\mathrm{M}+\mathrm{H}]^{+} 337.3$; found 337.3.

\section{Synthesis of 5-formylbenzene-1,2,3-triyl tris(undec-10-enoate)} (CL)

10-undecenoyl chloride (1.98 g, $9.78 \mathrm{mmol})$ was added dropwise into a THF solution $(15.0 \mathrm{~mL})$ containing 3,4,5-trihydroxybenzaldehyde $(508 \mathrm{mg}, 3.30 \mathrm{mmol})$ and triethylamine $(2.1 \mathrm{~mL}$, $14.6 \mathrm{mmol}$ ) over $20 \mathrm{~min}$ at $-30{ }^{\circ} \mathrm{C}$. The mixture was then warmed to room temperature and was stirred for $14 \mathrm{~h}$. After the reaction was completed, the reaction mixture was passed 
through a Celite pad (two times), and the filtrate was evaporated under reduced pressure to yield $\mathbf{C L}$ as a yellow oil $(2.0 \mathrm{~g}, 94 \%$ yield). ${ }^{1} \mathrm{H}$ NMR (500 MHz, $\left.\mathrm{CDCl}_{3}, \mathrm{ppm}\right): \delta 1.32-1.40(\mathrm{~s}, 30 \mathrm{H}$, 15C $\mathrm{CH}_{2}$ ) 1.70-1.76 (quint, $J=7.5 \mathrm{~Hz}, 6 \mathrm{H}, 3 \mathrm{CH}_{2}$ ), 2.02-2.06 (quart, $\left.J=7.0 \mathrm{~Hz}, 6 \mathrm{H}, 3 \mathrm{CH}_{2} \mathrm{CH}=\mathrm{CH}_{2}\right), 2.53-2.56(\mathrm{t}, J=7.5 \mathrm{~Hz}, 6 \mathrm{H}$, $3 \mathrm{CH}_{2} \mathrm{COO}-$ ), 4.92-5.01 (m, $J=10.2$ and $17.1 \mathrm{~Hz}, 6 \mathrm{H}, 3 \mathrm{CH}=$ $\left.\mathrm{CH}_{2}\right)$, 5.77-5.85 (m, $\mathrm{J}=16.7,16.8$ and $\left.17.0 \mathrm{~Hz}, 3 \mathrm{H}, 3 \mathrm{CH}=\mathrm{CH}_{2}\right)$, 7.64 (s, 2HAr, 2CH), $9.92 \mathrm{ppm}(\mathrm{s}, 1 \mathrm{H},-\mathrm{COH}) .{ }^{13} \mathrm{C}\left\{{ }^{1} \mathrm{H}\right\}$ NMR (125 $\mathrm{MHz}, \mathrm{CDCl}_{3}$, ppm): $\delta 24.9\left(\mathrm{CH}_{2}\right), 29.0\left(\mathrm{CH}_{2}\right), 29.1\left(\mathrm{CH}_{2}\right), 29.2$ $\left(\mathrm{CH}_{2}\right), 29.3\left(\mathrm{CH}_{2}\right), 29.4\left(\mathrm{CH}_{2}\right), 33.8\left(\mathrm{CH}_{2}\right), 114.3\left(\mathrm{CH}=\mathrm{CH}_{2}\right)$, $121.7(\mathrm{CH}), 134.0(\mathrm{Ar}), 139.2\left(\mathrm{CH}=\mathrm{CH}_{2}\right), 139.9(\mathrm{Ar}), 144.5(\mathrm{Ar})$, 170.5 (-COO-), 189.5 ppm (-CHO). APCI-MS: calculated for $\mathrm{C}_{40} \mathrm{H}_{60} \mathrm{O}_{7}[\mathrm{M}+\mathrm{H}]^{+}$652.43; found 652.4.

\section{General procedure for synthesis of polymers by acyclic diene metathesis (ADMET) polymerization using ruthenium catalysts}

A typical procedure for synthesis of polymer (P1) by ADMET polymerization (Table 1, run 8) is as follows. The monomer (M1, $330 \mathrm{mg}, 1.0 \mathrm{mmol}$ ) was loaded into a $25 \mathrm{~mL}$ sealed Schlenk-type tube. The $2^{\text {nd }}$ generation Grubbs catalyst G2, $\mathrm{RuCl}_{2}\left(\mathrm{PCy}_{3}\right)\left(\mathrm{H}_{2}-\right.$ IMes)(CHPh) (0.0127 g, $1.5 \mathrm{~mol} \%$ ) was dissolved in $0.4 \mathrm{~mL}$ of dichloromethane and transferred into a sealed Schlenk-type tube. The reaction mixture was magnetically stirred in an oil bath set at $50{ }^{\circ} \mathrm{C}$ under nitrogen atmosphere for $30 \mathrm{~min}$ (the valve was opened and connected to the vacuum/nitrogen line). The mixture was then placed into a liquid nitrogen bath to remove ethylene gas from the reaction medium by opening the valve connected to the vacuum line for a short period (less than $1 \mathrm{~min}$ ), and the valve was then closed and the tube was placed into the oil bath to continue the reaction. This is the similar procedure for synthesis of all-trans poly(9,9-dialkyl-fluorene-2,7-vinylene)s by the ADMET polymerization, ${ }^{26}$ and the apparatus was shown in ref. 26a. The procedure removing ethylene was repeated with a certain period (30 min for the first time then every $1.0 \mathrm{~h}$ ). The polymerization mixture was then cooled to room temperature and was quenched with excess ethyl vinyl ether while stirring for $1.0 \mathrm{~h}$. The resultant solution was then dissolved in chloroform $(2.0 \mathrm{~mL})$ for dilution, and the solution was added dropwise into the cold methanol (50 $\mathrm{mL}$ ). The solution was stirred for $1.0 \mathrm{~h}$, and the precipitates were then collected by filtration and dried in vacuo to yield P1 as rubbery solids $(0.299 \mathrm{~g}, 91 \%$ yield). A similar polymerization protocol was used for polymerization of M2 $(266 \mathrm{mg}, 1.0 \mathrm{mmol})$ and $\mathbf{M 3}$ (336 $\mathrm{mg}, 1.0 \mathrm{mmol}$ ) to yield polymers $\mathbf{P 2}$ and P3, respectively. The ${ }^{1} \mathrm{H}$ NMR and ${ }^{13} \mathrm{C}$ NMR spectra of obtained polymers with detailed peak assignments are shown in the ESI. $\uparrow^{23}$

P1 (sample run 8). ${ }^{1} \mathrm{H}$ NMR $\left(\mathrm{CDCl}_{3}\right): \delta 1.33,1.75-1.79,2.03-$ 2.07, 2.55-2.58, 3.37-3.38, 3.81, 5.39-5.67, 6.15-6.44, 6.75-6.79, 6.93-6.94. ${ }^{13} \mathrm{C}\left\{{ }^{1} \mathrm{H}\right\}$ NMR $\left(\mathrm{CDCl}_{3}\right): \delta 25.1,26.8,29.0,29.1,29.3$, 29.4, 32.6, 33.9, 34.1, 39.1, 55.9, 112.8, 120.7, 122.6, 128.6, 132.5, 138.2, 138.9, 151.0, 172.1.

PL1 (sample run 24). ${ }^{1} \mathrm{H}$ NMR $\left(\mathrm{CDCl}_{3}\right): \delta 1.32,1.75,1.97-$ 2.03, 2.56, 3.31-3.35, 3.80, 5.36-5.68, 6.18-6.44, 6.77, 6.92, 7.64, 9.92. ${ }^{13} \mathrm{C}\left\{{ }^{1} \mathrm{H}\right\}$ NMR $\left(\mathrm{CDCl}_{3}\right): \delta 25.2,26.8,29.0,29.1,29.3,29.4$, 32.6 , 33.9, 34.1, 39.1, 55.9, 112.8, 120.7, 122.6, 128.6, 132.5, 138.2, 138.9, 144.5, 151.2, 170.5, 172.2, 189.5 .
P2 (sample run 14). ${ }^{1} \mathrm{H} \mathrm{NMR}\left(\mathrm{CDCl}_{3}\right): \delta 1.27-1.28,1.38-1.41$, 1.60-1.63, 1.95-2.04, 2.26-2.29, 4.06, 5.33-5.42. ${ }^{13} \mathrm{C}\left\{{ }^{1} \mathrm{H}\right\}$ NMR $\left(\mathrm{CDCl}_{3}\right): \delta 25.2,25.9,28.3,29.2,29.3,29.4,29.5,32.3,32.7,32.8$, 34.5, 64.3, 130.4, 174.1 .

P3 (sample run 19). ${ }^{1} \mathrm{H} \mathrm{NMR}\left(\mathrm{CDCl}_{3}\right): \delta 1.29,1.61,1.96,2.28$, 4.05, 5.38. ${ }^{13} \mathrm{C}\left\{{ }^{1} \mathrm{H}\right\}$ NMR $\left(\mathrm{CDCl}_{3}\right): \delta 25.2,26.0,28.3,29.3,29.4$, 29.5, 29.6, 29.7, 29.8, 29.9, 32.7, 34.5, 64.5, 130.5, 174.1 .

\section{Conflicts of interest}

There are no conflicts of interest to declare.

\section{Acknowledgements}

The authors gratefully acknowledge the financial support provided by Thammasat University Research Fund under the TU Research Scholar, Contract No. 2/14/2560, and the international collaboration research program sponsored by Tokyo Metropolitan University (TMU). The project is partly supported by Grant-in-Aid for Challenging Exploratory Research (18K18981), Japan Society for the Promotion of Science (JSPS).

\section{Notes and references}

1 (a) L. M. Lillie, W. B. Tolman and T. M. Reineke, Polym. Chem., 2017, 8, 3746-3754; (b) M. Nasiri and T. M. Reineke, Polym. Chem., 2016, 7, 5233-5240; (c) J. J. Gallagher, M. A. Hillmyer and T. M. Reineke, ACS Sustainable Chem. Eng., 2015, 3, 662-667; (d) M. A. Hillmyer and W. B. Tolman, Acc. Chem. Res., 2014, 47, 2390-2396; (e) O. Coulembier, P. Degée, J. L. Hedrick and P. Dubois, Prog. Polym. Sci., 2006, 31, 723-747.

2 R. Mülhaupt, Macromol. Chem. Phys., 2013, 214, 159-174.

3 (a) M. A. R. Meier, J. O. Metzger and U. S. Schubert, Chem. Soc. Rev., 2007, 36, 1788-1802; (b) U. Biermann, U. Bornscheuer, M. A. R. Meier, J. O. Metzger and H. J. Schäfer, Angew. Chem., Int. Ed., 2011, 50, 3854-3871.

4 J. Zakzeski, P. C. A. Bruijnincx, A. L. Jongerius and B. M. Weckhuysen, Chem. Rev., 2010, 110, 3552-3599.

5 H. Kobayashi and A. Fukuoka, Green Chem., 2013, 15, 17401763.

6 (a) W. C. Shearouse, L. M. Lillie, T. M. Reineke and W. B. Tolman, ACS Macro Lett., 2015, 4, 284-288; (b) F. Fenouillot, A. Rousseau, G. Colomines, R. Saint-Loup and J. P. Pascault, Prog. Polym. Sci., 2010, 35, 578-622.

7 P. A. Wilbon, F. Chu and C. Tang, Macromol. Rapid Commun., 2013, 34, 8-37.

8 H. Mutlu and M. A. R. Meier, Eur. J. Lipid Sci. Technol., 2010, 112, 10-30.

9 A. Gandini and T. M. Lacerda, Monomers and Polymers from Chemically Modified Plant Oils and their Fatty Acids, Polymers from Plant Oils, John Wiley \& Sons, Inc., Hoboken, NJ, USA, and Scrivener Publishing LLC, Beverly, MA, USA, 2nd edn, 2019, pp. 33-82.

10 (a) J. E. Schwendeman, A. C. Church and K. B. Wagener, Adv. Synth. Catal., 2002, 344, 597-613; (b) A. Gandini and T. M. Lacerda, Metathesis Reactions Applied to Plant Oils 
and Polymers Derived from the Ensuing Products, Polymers from Plant Oils, John Wiley \& Sons, Inc., Hoboken, NJ, USA, and Scrivener Publishing LLC, Beverly, MA, USA, 2nd edn, 2019, pp. 83-108.

11 P. Dannecker, U. Biermann, A. Sink, F. R. Bloesser, J. O. Metzger and M. A. R. Meier, Macromol. Chem. Phys, 2019, 220, 1800400.

12 A. Rybak and M. A. R. Meier, ChemSusChem, 2008, 1, 542547.

13 (a) P. Dannecker, U. Biermann, A. Sink, F. R. Bloesser, J. O. Metzger and M. A. R. Meier, Macromol. Chem. Phys, 2019, 220, 1800400; (b) T. Lebarbé, M. Neqal, E. Grau, C. Alfos and H. Cramail, Green Chem., 2014, 16, 1755-1758; (c) H. Mutlu and M. A. R. Meier, Macromol. Chem. Phys., 2009, 210, 1019-1025.

14 L. Rojo, B. Vazquez, J. Parra, A. López Bravo, S. Deb and J. San Roman, Biomacromolecules, 2006, 7, 2751-2761.

15 (a) T. Yoshimura, T. Shimasaki, N. Teramoto and M. Shibata, Eur. Polym. J., 2015, 67, 397-408; (b) D. Guzmán, X. Ramis, X. Fernández-Francos, S. De la Flor and A. Serra, Eur. Polym. J., 2017, 93, 530-544.

16 (a) M. Shibata, N. Tetramoto, A. Imada, M. Neda and S. Sugimoto, React. Funct. Polym., 2013, 73, 1086-1095; (b) M. Neda, K. Okinaga and M. Shibata, Mater. Chem. Phys., 2014, 148, 319-327.

17 (a) D. F. Taber and K. J. Frankowski, J. Org. Chem., 2003, 68, 6047-6048; (b) K. A. Alexander, E. A. Paulhus, G. M. L. Lazarus and N. E. Leadbeater, J. Organomet. Chem., 2016, 812, 74-80.

18 (a) J. Moïse, S. Arseniyadis and J. Cossy, Org. Lett., 2007, 9, 1695-1698; (b) H. Bilel, N. Hamdi, F. Zagrouba, C. Fischmeister and C. Bruneau, RSC Adv., 2012, 2, 95849589.

19 D. Le, C. Samart, K. Tsutsumi, K. Nomura and S. Kongparakul, ACS Omega, 2018, 3, 11041-11049.

20 (a) P. Thirukumaran, A. Shakila and S. Muthusamy, $R S C$ Adv., 2014, 4, 7959-7966; (b) B. G. Harvey, C. M. Sahagun, A. J. Guenthner, T. J. Groshens, L. R. Cambrea, J. T. Reams and J. M. Mabry, ChemSusChem, 2014, 7, 1964-1969.

21 (a) K. Hu, D. Zhao, G. Wu and J. Ma, Polym. Chem., 2015, 6, 7138-7148; (b) K. Hu, D. Zhao, G. Wu and J. Ma, RSC Adv., 2015, 5, 85996-86005.

22 A. Llevot, E. Grau, S. Carlotti, S. Grelier and H. Cramail, Polym. Chem., 2015, 6, 7693-7700.
23 K. Nomura, S. Takahashi and Y. Imanishi, Macromolecules, 2001, 34, 4712-4723.

24 Selected NMR spectra of monomers (M1-M3), cross-linker (CL) and polymers (P1-P3, PL1) are shown in the ESI. $\dagger$ Selected DSC thermograms in the resultant polymers are also shown in the ESI. $\dagger$

25 For example, selected review in ADMET polymerization (a) E. B. Berda and K. B. Wagener, in Polymer Science: A Comprehensive Reference, ed. K. Matyjaszewski and $\mathrm{K}$. Müllen, Elsevier BV, Amsterdam, 2012, vol. 5, pp. 195-216; (b) E. B. Berda and K. B. Wagener, in Synthesis of Polymers; New Structures and Methods, ed. D. Schluter, C. Hawker and J. Sakamoto, Wiley-VCH, Weinheim, Germany, 2012, pp. 587-600.

26 Related experimental procedure for synthesis of all-trans poly(9,9'-dialkyl-fluorene-2,7-vinylene)s by ADMET polymerization, see: (a) K. Nomura, H. Morimoto, Y. Imanishi, Z. Ramhani and Y. Geerts, J. Polym. Sci., Part A: Polym. Chem., 2001, 39, 2463; (b) N. Yamamoto, R. Ito, Y. Geerts and K. Nomura, Macromolecules, 2009, 42, 5104.

27 For example (a) Handbook of Metathesis, ed. R. H. Grubbs, Wiley-VCH, Weinheim, Germany, 2003; (b) Olefin Metathesis: Theory and Practice, ed. K. Grela, John Wiley \& Sons, Inc., Hoboken, New Jersey, USA, 2014; (c) Handbook of Metathesis, ed. R. H. Grubbs and A. G. Wenzel, WileyVCH, Weinheim, Germany, 2nd edn, 2015, vol. 1.

28 For examples: (a) P. Dannecker, U. Biermann, A. Sink, F. R. Bloesser, J. O. Metzger and M. A. R. Meier, Macromol. Chem. Phys., 2019, 220, 1800400; (b) T. W. Gaines, T. Nakano, Y. Chujo, E. B. Trigg, K. I. Winey and K. B. Wagener, ACS Macro Lett., 2015, 4, 624-627; (c) R. R. Parkhurst, S. Balog, C. Weder and Y. C. Simon, RSC Adv., 2014, 4, 53967-53974; (d) O. Türünç and M. A. R. Meier, Green Chem., 2011, 13, 314-320; (e) A. Rybak and M. A. R. Meier, ChemSusChem, 2008, 1, 542547.

29 Synthesis of long-chain aliphatic polyesters: (a) F. Stempfle, B. S. Ritter, R. Mülhaupt and S. Mecking, Green Chem., 2014, 16, 2008-2014; (b) A. Rybak and M. A. R. Meier, ChemSusChem, 2008, 1, 542-547.

30 F. Stempfle, P. Ortmann and S. Mecking, Chem. Rev., 2016, 116, 4597-4641.

31 V. V. Korshak and S. V. Vinogradova, Polyesters, Pergamon Press, Oxford, UK, 1965. 